left broad ligament, which was secured by the clamp of Mr. Wm. Thomas. The peritoneum generally was thickened, and studded with flat masses like adherent lymph. The bleeding from the torn surfaces was not great, and was arrested by torsion and the actual cautery. It was observed that the divisions made by the scissors did not present any bleeding points. An elastic winged catheter, with additional and free boles above the wings, was placed behind the uterus through the vagina. The wound was closed with carbolised catgut, and the abdomen well supported.

She rallied fairly subsequently, and had some hours' s]eep through the night. Without any special symptoms she died suddenly the following day, twenty hours after the operation.

Autopsy, twetve hours after death.-About thirty ounces of reddish serous fluid was found in the peritoneal cavity, none in Douglas's pouch, and no clots. The right ovary was normal in size. The intestines were not distended with flatus, and were very empty. The liver was soft and pulpy, and presented evidences microscopically of fatty degeneration. Nothing unusual was noticed beyond this.

The above is an abridged account giving the main features of interest in connexion with the case. The value of the toothed scissors in the separation of adhesions was especially noticed; it should be remarked that in using them no onward movement should be made as in ordinary blades, but simply division in situ, firmly and slowly. Additional experience may confirm their use as a valuable adjunct in this part of the operation, the heavier and more solid forms being better adapted for crushing and dividing dense and resisting tissues.

Birmingham.

\section{d 筑intor}

\section{HOSPITAL PRACTICE, BRITISH AND FOREIGN.}

Nulla autem est alia pro certo nos endi via, nisi quamplurimas et morborum et dissectionum historias, tum aliorum, tum proprias collectas habere, et inter se comparare,-Morgagni De Sed. et Caus. Morb., lib.iv. Procminm.

\section{GUY'S HOSPITAL.}

\section{ACUTE ARTICULAR RHEOMATISM TREATED BY ACIDS;} REMARKS.

(Under the care of Dr. WIrKs.)

IN recently making some comments on the treatment of acute rheumatism, Dr. Wilks expressed a considerable distrust of the ordinary methods. He remarked that we do not yet possess an accurate knowledge of the essential cause of the disease, nor of the mode of its operation. We are, in fact, ignorant of the natural history of the disease. Medical practitioners are too apt to be credulous in matters of therapeusis, and are not sufficiently careful always to differentiate between effects and coincidences. Usually, for instance, the diagnosis of acute articular rheumatism is regarded as a sure and certain indication for the exhibition of alkaline remedies, and these remedies are persisted in in every condition or modification of the disease, without the slightest evidence of a beneficial influence resulting therefrom. Nay, it frequently happens that the more severe the disease the stronger does the belief in the particular remedy become, and medical men not uncommonly allege in support of the efficacy of the treatment that the complications were of the most serious nature. If the patient recover after having had severe heart disease or symptoms referable to an affection of the nervous system, it is regarded as proof positive of the value of the remedy. Whereas we can not only not be certain that recovery did take place as a result of the treatment, but that it did not occur in spite of the vaunted remedies. On the other hand, some have asserted that there is no known cure for acute rheumatism, and that mint-water will answer every purpose. This is Dr. Wilks's opinion, and it was merely to strengthen this view that he gave mineral acids in the subjoined case, never supposing that they would do good or harm. Dr. Wilks maintains that, until we know everything concerning the disease, and especially the relation between the joint affection and the internal complications, we have no scientific basis for the selection of remedies. It is even doubtful whether the subsidence of the arthritic inflammation during the course of the disease is desirable, for in all fatal forms of rheumatism this is usually seen to occur. It may be remarked, however, that sometimes, in cases of internal complication, it does seem as if large doses of potash or of quinine have some influence in arresting the disease. In several cases treated by quinine Dr. Wilks has noticed the urine to become alkaline on recovery, as if this were the natural process of cure; as is seen also in typhoid fever. The same thing occurred in the present case.

For the following notes we are indebted to Mr. J. C. Ferrier.

G. W-, a well-nourished man, aged thirty-five, was admitted on January 14th. A week before this he began to suffer pain in the hip-joints; subsequently both knees, and the right shoulder, wrist, and hand were affected. The pain in the joints was preceded by a feeling of coldness, but there was no actual rigor.

On admission the left knee was swollen from the presence of fluid within the joint. The right hand also was swollen and painful. A systolic bruit could be distinctly heard over the base of the heart, and extending a short way along the aorta. A venous hum was audible at the root of the neck. Perspiration was acid; temperature $101^{\circ}$; pulse 96 ; respiration 24. Tongue moist and covered with a white fur. The urine was acid, and contained a large quantity of lithates.

Orderea fifteen drops of dilute nitro-hydrochloric acid every four hours, and a diet to consist of milk, bread, and beef-tea.

Jan. 16th.-Temperature $101 \cdot 8^{\circ}$.

19th.-Joints previously affected are better, but the right hand and both knees are still painful. Systolic basic bruit still very loud.

20th.-Temperature 102.8. Perspires freely.

23rd. - Hands and knees almost well. Temperature $101 \cdot 2^{\circ}$

28th.-None of the joints are swollen, but some feel stiff and sore. Bruit hardly audible. Urine alkaline.

Feb. 2nd.-Bruit almost entirely gone. The patient is convalescent.

\section{ST. BARTHOLOMEW'S HOSPITAL.}

A SERIES OF CASES OF COMPOUND FRACTURES, SUCCESSFULLY TREATED ON CONSERVATIVE PRINCIPLES.

(Under the care of Mr. CALLENDER.)

The following conclude this series of cases, commenced at page 162. It will be seen that the results of the subjoined cases were as happy as those of the cases already reported. For the notes we are indebted to Mr. E. Jepson, house-surgeon.

Compound comminuted fracture of the left olecranon, communicating with the elbow-joint. — William B-, aged fiftytwo, on June 26th, whilst standing on a ladder, lost his balance and fell to the ground, his elbow striking the pavement violently. The injury produced a compound fracture of the left olecranon nearly one inch from its extremity, which was followed by rapid effusion into the elbow-joint. The limb was placed on an angular splint fixed at an angle of about $140^{\circ}$.

July 2nd.-Inflammation set in around the elbow, and two punctures were subsequently made to let out the pus the redness and swelling increasing to some extent during the following week.

17th.-Slight erythema involved the whole arm, and on the 18th it was thought advisable to remove the arm from the splint to a pillow for a few days; but four days afterwards, the erythema subsiding, the arm was again put on the splint and slung. After this he progressed favourably, the wound healed and the swelling of the elbow subsided, and on Oct. 30 th the patient was well.

On Nov. 20 th he was sent to the Convalescent Hospital. The arm was at this time stiff, in a slightly flexed position. Several attempts had been made to bend the joint, kut so much local pain was thus occasioned that it was found 
necessary to desist for a time. On the patient's return from Highgate, if it is found impossible to obtain joint movement by manipulation, other means may be necessary to bring the forearm into a more serviceable position.

Compound fracture of the femur.-John O-, aged fiftyfour, was admitted Jan. 11th, 1873, suffering from compound fracture of the right femur about its middle, and with very severe bruising of the adjacent soft parts, a large quantity of venous blood having been extravasated and much of it escaping through a wound situated on the front of the thigh. The limb having been secured with an ordinary long splint, and the bleeding ceasing with rest and position, the wound was dressed with carbolised oil on lint, and for a time the case progressed favourably. After five weeks, however, the soft parts about the fracture proved to be so severely damaged that suppuration was established around the fracture, and pus was discharged in front and made a second way out at the back of the thigh. Large quantities of pus drained away for many weeks. During all this time there was no attempt at union. Slowly the discharge diminished; but it was not until weeks had elapsed that the sinuses finally closed. Meanwhile, by the retention of the long splint and by weight extension, the thigh had been kept fairly at rest; yet it was impossible to avoid some shortening. In the end the limb was encased in strong gutta-percha splints; and, the suppuration having ceased, the union of the bones began, and the patient is now convalescing. The limb has been saved; but there is an inch and a half of shortening.

\section{MIDDLESEX HOSPITAL.}

\section{A SELF-ADJUSTING SLING ARM-SPLINT FOR PATIENTS CONFINED TO BED.}

Recognising the value of Mr. Callender's sling-splint for the arm, the authorities of this hospital at once determined to adopt it; but it was found that the apparatus of $\mathrm{Mr}$. Callender was not suited for the beds at Middlesex Hospital. To remove this objection, the senior house-surgeon, Mr. H. Hammond Smith, has introduced several modifications, by which the splint may be used with almost any bed.

The apparatus consists of a wrought-iron support, a sling, and a counterweight. The support is made of an iron bar bent at a right angle, the vertical part of which is round and works in a socket fixed by hooks or screws to the bedhead, so that it can be moved to right or left readily by the patient when necessary. At the angle of the support is a small iron pulley over which the cord of the sling runs, and on the horizontal arm is another pulley, which can be moved backwards or forwards at pleasure.

The sling is made of strong canvas, with four holes on each side, and supported by four cords with hooks, which can be so placed in the holes of the sling as to give the arm or hand any angle or position. These sling-cords are attached to the single cord which passes over the pulleys, and has at its other extremity a bag containing shot, so that the weigbt may be increased or diminished as occasion requires.

The advantages of this sling are, that the patient need not constantly have his arm in one position, that the position may be altered without assistance, and that it can be applied to almost any bed. It has been used with great success in cases of cellulitis of the arm and hand, in amputation about the hand, and in one case of compound fracture of the humerus.

\section{ROYAL SURREY COUNTY HOSPITAL, GUILDFORD.}

RETENTION OF URINE FROM ENLARGED PROSTATE GLAND, RELIEVED BY THE PNEUMATIC ASPIRATOR.

(Under the care of Mr. HenRY TAYLor.)

USEFUL as puncture through the rectum is for the relief of retention of urine from obstruction of the urethra, there are, nevertheless, certain conditions in which its application is attended with great difficulty, if not with actual failure. Chief among these difficulties is an enlarged prostate. In such a case there is a danger lest the trocar and canula should not clear the prostate; or, supposing this difficulty to be overcome, there is the more serious danger of puncturing. the bladder at too high a point, so that the recto-vesical fold of the peritoneum is injured. For such cases suprapubic puncture affords the best prospect of success, and of the various methods proposed for the performance of this operation none is more satisfactory or apparently attended with less mischief than the puncture by Dieulafoy's pneumatic aspirator. Experience alone will enable us to fully determine the real merits of this procedure, but so far it has been attended with such success as to warrant its repetition in cases of retention of urine from impassable stricture due to enlargement of the prostate.

For the notes of the following case we are indebted to Dr. F. Warner.

William M- aged seventy-four, a farrier, was brought into the hospital on the evening of October 3rd, 1873. He had been unable to pass any water since 2 A.m. of that day, and catheterism had been attempted by two surgeons in the neighbourhood without success. He was in great pain, with his bladder fully distended, and reaching above the umbilicus. He stated that he had found occasional difficulty in passing water for about four years, and had been obliged to have a catheter passed on three different occasions, and that there had never been any difficuity in so doing. $\mathrm{He}$ also said he had occasionally passed a little blood in his urine. Catheterism was attempted again by the housesurgeon (large prostatic catheter), and subsequently by Mr. Taylor, but both attempts were unsuccessful, and the instrument was found to pass into a long false passage and free hæmorrhage occurred. On rectal examination the prostate was found so much enlarged that its posterior extremity could not be reached, thus forbidding puncture of the bladder in this situation. The smallest-sized needle but one of Weiss's pneumatic aspirator was then passed into the bladder above the pubis. Trenty-six ounces of urine were drawn off, and a few minutes after the urine began to flow the patient fell asleep. The last portion of urine was tinged with blood.

Next morning (Oct. 4th) catheterism was again attempted with silver and elastic catheters, but failed. The aspirator was then used again as before and thirty ounces were drawn off. Towards evening he passed two ounces by his own efforts.

Oct. 5th.-Twenty-eight ounces were drawn off by the aspirator in the morning, and twenty ounces at night, the urine being quite clear and not offensive.

6th.-By the aspirator twenty-four ounces were drawn off in the morning, and thirty ounces in the evening.

7th.-'Thirty-three ounces were drawn off by the aspirator. When the bladder was emptied Mr. Taylor passed a No. 8 elastic catheter with ease, and tied it in. By the evening he had passed thirty-eight ounces of urine. In all, the aspirator was used seven times, the patient frequently asking to have it employed. No abdominal tenderness or other sign of mischief from it resulted.

10th. - The catheter was withdrawn with a small calculus fixed in its eje. The catheter was subsequently passed three times a day.

17 th.-He became very feverish. Pulse 100 ; tempera. ture $104^{\circ}$. Urine became somewhat thick and offensive; appetite falling off.

19th.-Passed urine without use of catheter; had a slight rigor, and the general strength much declined. The appetite failed. He became gradually weaker, and died on Oct. 22 nd. Autopsy, Oct. 23rd.-No trace of punctures in bladder or abdominal walls as seen from inside. Bladder enormously thickened, its muscular fibres standing out prominently; mucous membrane deeply injected. The prostate gland measured two inches from before backwards. The bladder and prostate together weighed eleven ounces. Right kidney mottled, slightly lobulated, showed some cysts, and was evidently the seat of chronic granular degeneration; there were a few purulent points in the cortex; weight five ounces and a half. Ieft kidney large, pale, full of small purulent spots; weight ten ounces. A large false passage was found passing from the urethra between the prostate and rectum, and nearly perforating the latter. 